\title{
¿HASTA DÓNDE ESTAMOS DISPUESTOS A COMPROMETERNOS CON LA LIBERTAD RELIGIOSA?
}

Alessandro Caviglia Marconi*

\section{RESUMEN:}

Uno de los derechos fundamentales reconocido internacionalmente en la actualidad lo constituye el de libertad religiosa, que nos faculta a profesar libremente una creencia religiosa sin ser perseguido u hostigado por el Estado o por sectores de la sociedad a la que se pertenece. En este artículo, el autor asume que en una sociedad democrática y liberal los ciudadanos han de gozar de este derecho a profesar sus creencias religiosas, por más que éstas resulten extravagantes a los demás miembros de la sociedad, pero este derecho fundamental ha sido violado permanentemente en sociedades democráticas contemporáneas. Se reflexiona que esto acontece por falta de una cultura liberal, que separe adecuadamente la esfera del Estado de la esfera religiosa, o en sociedades donde dicha separación se ha realizado pero la situación de conflictos armados que hace que surjan nuevas formas de tiranía.

PALABRAS CLAVE: Derechos fundamentales, libertad religiosa, sociedad liberal, cultura liberal, Estado.

\section{UNTIL WHAT LIMIT WE ARE WILLING TO GET ENGAGED WITH THE RELIGIOUS FREEDOM?}

\begin{abstract}
One of the main rights, internationally and currently acknowledged is the religious freedom, which let us to freely profess a religious belief without being persecuted or bothered by the State or by society sectors which they belonged to. In this article, the author assumes that in a democratic and liberal society, citizens must enjoy this right to profess their religious beliefs, even though they will result extravagant to the other members of the society. However, this fundamental right has been permanently violated in contemporary democratic societies. This happens because of a lack of liberal culture, which might adequately separate the State from the religious sphere, or in societies where such separation has been executed however, the situation of settled conflicts may lead in new ways of tyranny.
\end{abstract}

KEYWORDS: Fundamental right, religious freedom, freedom society, liberal culture, State.

*Licenciado en Filosofía por la Pontificia Universidad Católica del Perú. Maestro en Filosofía por PUCP. Profesor Ordinario del Departamento de Filosofía y Teología en la Universidad Femenina. Docente en la Universidad Antonio Ruiz de Montoya y en la Universidad San Martín de Porres. 
Uno de los derechos fundamentales reconocido internacionalmente en la actualidad lo constituye el de libertad religiosa. Cercano al derecho de opinión, se trata del derecho a profesar libremente una creencia religiosa sin ser perseguido u hostigado por el Estado o por sectores de la sociedad a la que se pertenece. En una sociedad democrática y liberal los ciudadanos han de gozar de este derecho a profesar sus creencias religiosas, por más que éstas resulten extravagantes a los demás miembros de la sociedad. ${ }^{18}$ Sin embargo, ese derecho fundamental ha sido violado permanentemente en sociedades democráticas contemporáneas, en algunos casos por falta de una cultura liberal, que separe adecuadamente la esfera del Estado de la esfera religiosa, o en sociedades donde se supone dicha separación se ha realizado pero la situación de conflicto armado que significa el combate contra el terrorismo internacional ha hecho que surjan nuevas formas de tiranía.

\section{La libertad religiosa a elegir cómo creer.}

Se ha estudiado anteriormente las violaciones a la libertad de creencia religiosa que provienen del entorno social y político, de modo que se ha hostigado a las personas por lo que creen o por en quién creen. Quiero concentrarme esta vez en otro aspecto del problema de la libertad religiosa que no ha sido suficientemente explorado. Lo constituye no tanto por la libertad sobre qué o en quién creer (es decir, si se es cristiano, musulmán o judío, por ejemplo), sino la libertad a elegir cómo creer lo que ser cree. Gran parte de las guerras religiosas que asolaron el continente europeo durante el siglo XVI han tenido como foco disputas respecto al cómo de la creencia religiosa más que el quéde la misma. ${ }^{20}$

¿A qué me refiero con esta distinción entre el qué y el cómo en cuestiones de creencias religiosas? El derecho a abrazar una creencia religiosa -es decir, el qué

\footnotetext{
${ }^{18}$ El derecho a profesar creencias religiosas o a tener un tipo de vida que resulta extraña al resto de la sociedad es tratado por John Stuart Mill en Sobre la libertad. Cf. Cap.IV De los límites de la autoridad de la sociedad sobre el individuo.

19 El surgimiento de las sociedades democráticas liberales ha significado la distinción de la esfera del poder y la esfera religiosa, haciéndose posible que los diferentes grupos religiosos puedan convivir en una sociedad donde el Estado no privilegia a ninguna doctrina religiosa particular. No todas las sociedades democráticas contemporáneas han completado este proceso de separación. En muchas sociedades latinoamericanas la Iglesia Católica mantiene aún una cuota importante de poder político, proyección de su función tutelar del pasado. Por ejemplo, la institución del Te Deum en las fiestas patrias peruanas o la fuerte capacidad de presión que mantiene la Iglesia Católica en algunos parlamentos latinoamericanos, demostrando que falta profundizar la consolidación de una sociedad democrática y liberal.

20 Por ejemplo la persecución de los herejes tanto por la Inquisición Católica como por la ortodoxia protestante, especialmente calvinista. La historia se encuentra plagada de transes de persecución y masacre de herejes. Uno de ellos, destacable por lo sanguinario, tuvo lugar durante el siglo XIII bajo el papado de Inocencio III. El Albi, al sur de Francia, se había fortalecido una versión cristianismo de había bebido del maniqueísmo anticlerical de los tantos que plagaron Europa desde los inicios del medioevo. Los albigenses no sólo estaban casi todos convertidos a dicha versión del cristianismo sumamente crítica al papado (al igual que los llamas fraticelli, que derivaban de los franciscanos), sino que la región, gracias al trabajo y esfuerzo de los habitantes de Albi, había prosperado notablemente. Durante la última campaña orquestada por Inocencio III, organizada en 1214, al encontrar el primer pueblo numeroso de la región los soldados preguntaron cómo distinguir a los herejes de quiénes no lo eran. A ello encontraron como respuesta: "Matadlos a todos, Dios sabrá lo suyo". La masacre -y el saqueo- estaban justificada, pues Dios separará a los herejes de los fieles a la ortodoxia.
} 
creer- pertenece a una persona o a una comunidad y demarca una esfera de libertad que no puede ser vulnerada por otras personas o grupos que no comparten dicha creencia religiosa. Como comunidad podemos creer en Cristo, en Alá o tener otra creencia religiosa posible. El atentado contra la libertad de las comunidades de creyentes puede graficarse claramente con las cruzadas, en las cuales los cristianos agredieron a sus enemigos exteriores, que abrazan otros credos. El ejercicio de la violencia en estos casos se pretende justificado como una reacción legítima contra los impíos, es decir, contra aquellos que no creen en la "religión Verdadera".

Ahora bien, una cosa es creer en Cristo y otra cosa distinta es la manera en que uno viva dicha creencia. Respecto del cómo ya no se trata de la relación de la comunidad de creyentes con los que no creen sino se trata, más bien, de la relación entre creyentes al interior de la misma comunidad de fe. Así, por ejemplo, una cosa es creer en Cristo y otra distinta es la manera en la que se profese esa fe. Esta es la fuente de la que surge el ejercicio de la violencia conocida como combate de las herejías. Aquí la violencia es utilizada contra los enemigos que se hayan dentro de la comunidad de creyentes, como es sucedió con la Inquisición católica. Lo que me interesa es esclarecer este último aspecto, referente al modo de creer, porque sospecho que algunos de los males del mundo contemporáneo tienen sus raíces en ello.

En términos generales podría decirse que hay dos modos de asumir una creencia religiosa. El primero lo denominaré "doctrinario", mientras que al segundo lo llamaré "experiencial". Algo más, alguien quizás pueda objetar que hay mucha y no sólo dos maneras de creer.

Frente a ello he de aclarar que aquí se trata de dos actitudes que considero lo suficientemente abarcadoras como para cubrir gran parte del espectro de las creencias religiosas..$^{22}$

${ }^{21}$ Para el caso específico de las comunidades cristianas la distinción entre el qué (o en quién) creer y el cómo creer se presenta de este modo: en ellas las personas creen en Cristo (quién) y creen que Él es el Salvador (qué), pero tienen (o deberían tener) el derecho a elegir la manera (el cómo) de creer en Cristo y de creer que Él es el Salvador. Si bien la cuestión por el qué afecta directamente a lo doctrinario mientras que la cuestión referida al cómo se vincula con lo ritual, oracular y lo ético, no todo lo referente a lo doctrinal es agotado por el qué puesto que hay muchas maneras de interpretar y asumir un núcleo doctrinal. De hecho los núcleos doctrinales libres de toda interpretación no existen, sino que lo único con lo que contamos son doctrinas interpretadas. Las diferentes interpretaciones son diferentes modos de asumir los cuerpos doctrinarios.

22 Gustavo Gutiérrez es su Teología de la liberación. Perspectivas utilizó los términos “ortodoxia" y "ortopraxis" -es decir, creencia (cor)recta y acción (cor)recta- de modo análogo, aunque tal vez no del todo, a mi uso de los términos "doctrinario" y "experiencial". Sospecho que las etiquetas que uso no son del todo traducibles a los términos de Gutiérrez, pues detrás de la diferenciación que introduzco se encuentra la distinción kantiana entre razón pura y razón práctica de una manera que resulta problemático encontrar en la teología de la liberación. La distinción kantiana entre ambos tipos de racionalidades procura encarar el complicado problema filosófico de la relación entre la teoría y la práctica de una manera distinta a la forma en que Gutiérrez procura hacerlo. 


\section{Las creencias religiosas asumidas de modo doctrinario.}

La primera forma de tener una creencia religiosa la he denominado "doctrinaria", pero ello no significa que todo el que asuma un sistema doctrinario en su vida de fe está asumiendo sus creencias religiosas de manera doctrinaria. Esto último sucede cuando la persona o el grupo exigen a todos los demás creyentes a relacionarse con los dogmas (o las verdades de fe) de la manera en la que ésta se relaciona, es decir, asumirlos de manera literal. Un $^{23}$ segundo elemento de la creencia doctrinariamente asumida consiste en que reduce y empobrece la identidad de los creyentes, es decir, genera una autoimagen reducida y empobrecida en la persona de los fieles. Finalmente, un tercer elemento de la creencia doctrinaria es el político, que conduce a los creyentes a movilizarse -motivado por líderes político-religiosos - contra sus enemigos internos a la comunidad de creyentes o a enemigos externos como son las otras comunidades religiosas.
La conjunción de estos elementos esconde potencialidades sumamente violentas frente a los correligionarios como frente a los no creyentes. Así la $^{24}$ purgación de las creencias en la tristemente célebre lucha contra las herejías en el pasado del catolicismo y del protestantismo ha sido muestra de violencia contra los correligionarios. En tanto que la "guerra contra las otras religiones", que incluso tener su centro en torno al término "terrorismo internacional" - ya sea luchando contra el "demonio occidental" que se presenta como "cruzado del siglo XXI", o sea bajo la forma del "mal radical" que combatiremos con las fuerzas de Yavéh; esta guerra contra los otros (y en última instancia contra "el maligno") representa un potencial sumamente peligroso. De hecho hay algo de perverso en ello, aunque sea solamente el hecho de agredir e insultar a otro, o tomar las armas contra él por el hecho de que tiene otras creencias religiosas o en razón de que, compartiendo nuestras propias creencias, las asume de manera distinta.

23 La literalidad de los textos o de los dogmas o de ciertas verdades nunca es real, sino que es construida o definida por líderes de los grupos en cuestión, quiénes señalan en qué sentido han de interpretarse tanto los textos, como los dogmas y las verdades de fe. Cfr. Arens, Eduardo; La Biblia sin mitos. Una introducción crítica, Lima: CEP, 2004 Véase allí especialmente el apéndice titulado El fundamentalismo.

24 Respecto a la retórica estadounidense en su combate político-religioso contra el mal véase Berstein, Richard; El abuso del mal. La corrupción de la política y la religión desde el 11/9. Buenos Aires: Katz, 2006.

25 La disputa sostenida por Bartolomé de las Casas con Juan Ginés de Sepúlveda en el siglo XVI muestra aristas que lindan con los temas de la herejía y la impiedad. En la discusión teológica sobre el estatuto religioso de los indígenas americanos, se encuentran implicadas dos cosas diferentes. una, de orden teológico (referente a la salvación de los no bautizados); y, la otra, de orden político y económico (refiere a la legitimidad de la conquista y a la autoridad de los encomenderos para enriquecerse con el trabajo de los aborígenes como si de sus esclavos se tratara). Esta última cuestión es sumamente importante en la discusión sobre el entonces reciente Derecho de Gentes, así como la reflexión en torno al acceso a la justicia) que se estaba gestando con Francisco de Victoria en la época. Pero la primera de estas cuestiones tiene que ver con la pregunta sobre cómo considerar a los originarios americanos, puesto que la revelación no les había sido comunicada: ¿eran herejes?, ¿paganos? ¿o habría que considerarlos de alguna otra forma? Para explicase lo más importante en esta cuestión en un sentido existencial, se resolvió que gente no bautizada como ellos no irían al infierno ni al purgatorio -reservados a impíos y herejessino al limbo. El limbo se convirtió en el lugar- lejos de Dios- donde irían los no bautizados en general, y no sólo los no bautizados europeos. Recientemente el Papa Benedicto XVI ha declarado saludablemente que el limbo es una invención del imaginario popular sin sustento teológico. Sea como fuere, la creencia en el limbo generó mucho dolor en quienes perdieron a hijos antes de poder bautizarlos. 
Se suele llamar fundamentalista o integrista a quien se relaciona con los dogmas de un modo tan estrecho como para asumir una supuesta lectura literal de los mismos. Para éstas personas los dogmas tal cual ellos los interpretan definen por entero la fe en cuestión, de tal modo que quienes tengan interpretaciones distintas de éstos se encuentran profundamente en el error. El "error" consiste aquí no en que no crean en los dogmas, sino en que no lo hacen "correctamente". De tal manera que si se quiere salvar el alma de aquél o salvar la religión de los herejes hay que enmendar la manera en que los "hermanos desviados por el mal" creen lo que nosotros creemos. De ahí a pensar que todo tipo de violencia se legitima frente a la "perdición" hay un paso muy corto. Lo doctrinario o fundamentalista aquí no consiste es adherirse a dogmas específicos ni creer que el otro está es el error, sino más bien tener la militante idea de que es nuestro deber enmendarle la plana al otro respecto a su manera de creer.

Pero esta adhesión estrecha a ciertas verdades de fe es posible porque uno interpreta su identidad de manera empobrecida. Comúnmente las personas articulan su identidad a través de una pluralidad de lealtades. Por ejemplo, una persona puede ser católico, peruano, limeño, literato, tener una determinada orientación política, ser hispano parlante, o muy bien podría tener doble nacionalidad y haber crecido en un hogar bilingüe y haberse identificado adicionalmente con una tercera lengua y cultura que adquirió en la escuela a la que asistió. De esta manera en las personas hay una pluralidad de focos que configura una identidad compleja. El fundamentalismo se origina cuando se oscurecen los focos identitarios para resaltar exclusivamente uno de $\mathrm{lo}^{27}$ elementos que lo constituye. De esta manera, cuando la persona decide - o es inducida a- hacer valer sólo el hecho de que es católico, se produce en su vida un gran empobrecimiento y termina teniendo actitudes hostiles para con otros. Muchas veces sucede que en los conflictos sociales las personas sienten agredidas algunos de sus fuentes de identidad, que posteriormente pueden convertirse en la punta de lanza de las reivindicaciones, que muy bien podría oscurecer las otras fuentes de la identidad si las condiciones son propicias para ello.

Ahora bien, cuando las personas son inducidas o forzadas por las comunidades religiosas y sus líderes políticos a asumir ese empobrecimiento de su identidad se atenta contra su propia libertad. En cuestiones de libertades religiosas hay que tener en cuenta que una cosa es la libertad de los grupos a tener sus creencias religiosas y otra cosa es la libertad de las personas a asumir sus creencias de manera libre, por medio de coacciones internas o externas. La existencia de comunidades religiosas es un bien de nuestro mundo contemporáneo, pero no hay que olvidar que lo es en tanto que ellas expresan la libertad de creencia de las personas y no la sumisión de las mismas. No son, en ningún caso un bien en sí mismas. ${ }^{27}$

26 Maalouf, Amin; Identidades asesinas, Madrid: Alianza Editorial, 2002.

27 Sen, Amartya; Identidad y violencia. La ilusión del destino, Buenos Aires: Katz, 2007. 
En la páginas 215 y 216 de su texto (referido en el último pie) Sen expresa con claridad la crítica contra esta opción, que perfectamente podemos denominar "tradicionalismo" citando una observación que el emperador indio, Akbar realizó alrededor de 1590 respecto de la relación entre la razón libre y el tradicionalismo, en el marco de las reflexiones sobre la relación entre la fe y la razón. El emperador dice a su interlocutor y amigo Abul Fazl lo siguiente:

"La búsqueda de la razón" y el rechazo del tradicionalismo son tan brillan-temente obvios que están por encima de la necesidad de discutir. Si el tradicionalismo fuese apropiado los profetas simplemente habrían seguido a sus mayores (y no habrían traído nuevos mensajes).

Las creencias religiosas asumidas de modo experiencial.

El modo experiencial de asumir una creencia religiosa se distingue del modo doctrinal como lo teórico de lo práctico. Mientras que lo doctrinal consiste en asumir ciertas "verdades de fe" de un modo especificado, lo experiencial consiste en vivir ciertos ideales prácticos que sobrepasan con creces las verdades definidas dogmáticamente. ${ }^{28}$ Podríamos decir que estos ideales prácticos cons- tituyen el horizonte de fe en el que se insertan las "verdades de fe" dogmáticamente definidas. En este sentido creer de manera experiencial nos puede abrir a la tolerancia puesto que se entiende que en el trasfondo vital de nuestras creencias religiosas se encuentra la exigencia práctica de respetar a los otros aunque no compartan nuestras doctrinas. Esto de modo que podríamos considerar a las creencias de los fieles de otras religiones como creencias dignas de respeto y aprecio en vez de radicalmente erradas.

Se trata de una manera razonable de tener creencias religiosas porque se considera el derecho legítimo de los demás a tener sus propias creencias religiosas, e inclusive se ve la pluralidad como un valor del mundo contemporáneo, por ser expresión de las libertades. Al interior de las comunidades de fe el creyente experiencial respeta y valora la existencia de una pluralidad de formas de asumir las creencias religiosas. Incluso, el creyente doctrinal es respetado y valorado por el creyente vivencian, siempre que el primero sea respetuoso y no ejerza violencia contra otros. Respecto de las relaciones interreligiosas el creyente experiencial no sólo es respetuoso sino que valora la existencia de la pluralidad de creencias religiosas. En ningún momento muestra

\footnotetext{
${ }^{28}$ El retorno de lo religioso en nuestro mundo contemporáneo no sólo trajo el antiguo modo más doctrinario de asumir las creencias religiosas, sino que también significó el florecimiento del modo experiencial de asumirlas. De modo que lo religioso retorna no sólo como componente político y doctrinario en la escena mundial actual, sino como forma de vivir la esperanza que, en cierto modo, el fin de los grandes relatos revolucionarios había dejado deshabitada. Este retorno experiencial de lo religioso tiene algo de inédito, no por que antes no se haya propuesto asumir el cristianismo - $\mathrm{u}$ otra religión- en ese sentido. De hecho así lo propusieron Castellio, en el cristianismo protestante y ciertos intelectuales islámicos lo habían hecho, entre otros. Lo nuevo es que ahora la propuesta de asumir las religiones en sentido experiencial no es exclusividad de las élites intelectuales. Esto puede tener muchas causas, como la expansión de la educación y el mayor despliegue de las comunicaciones. Sea como sea han cada vez más personas que no están dispuestas a simplificar y empobrecer la riqueza de sus identidades plurales.
} 
hostilidad frente a otros por el hecho de que tienen credos religiosos distintos al suyo.

Estas actitudes son posibles por varios motivos. De un lado el creyente experiencial da prioridad a la caridad antes que a los aspectos dogmáticos. Por otra parte, sucede que su identidad no ha sufrido el estrechamiento de definirse sólo como creyente, sino también como perteneciente a una o varias comunidades políticas, perteneciente a una o varias comunidades lingüísticas, tener tal orientación política, tener tal profesión o cual afición, etc. Ello no necesariamente arrincona su dimensión religiosa, sino que le permite matizarla y enriquecerla, lo que significa tener una vida más amplia y rica. Además, le es posible tener esa actitud respecto a la religión porque no se encuentra capturado por el miedo frente a los demás, a la pluralidad del mundo humano o al inminente castigo divino que, según el fundamentalismo, sobrevendría a quién no cree "correctamente". Si bien pueden encontrar cosas que lo atemoricen, el temor no cierra su capacidad de reflexionar y de manejar los conflictos y desacuerdos propios de la convivencia social de manera razonable. La actitud fundamentalista, en cambio, se encuentra relacionada a la inseguridad y la ansiedad que muchas personas experimentan y que les obliga a refugiarse en formas de vivir y de creer tanto doctrinas religiosas como doctrinas laicas que le ofrecen una supuesta segundad y que, entre otras cosas, definen su identidad en contraposición a doctrinas opuestas. Esta manera de asumir las creencias se encuentra en sintonía con el últimamente tan ensalzado "conflicto entre civilizaciones". 29

\section{La apertura a la tolerancia y al diálogo interreligioso.}

Uno de los grandes humanistas del siglo XVI ha sido Sebastián Castellio, quien pensaba la libertad de conciencia en cuestiones religiosas como un don del Espíritu. Esta intuición lo condujo a considerar la tolerancia religiosa como un principio fundamental, de tal manera que se constituyó en el precedente de John Locke, el padre de la tolerancia de las sociedades democráticas modernas y contemporáneas. Castellio, en su controversia con el fundamentalismo de Jean Calvino asienta en las mismas Escrituras su principio de tolerancia para con quien cree de manera distinta - es decir, frente a todos aquellos a los que tanto la Inquisición católica como el fundamentalismo protestante de Calvino acusa de herejes y considera dignos de penas de muerte tortuosas y ejemplares -. Castellio afirmará lo siguiente: 'Las verdades de la religión son por naturaleza misteriosas, y desde hace más de mil años constituyen la materia de una inagotable controversia, en la que la sangre no dejará

\footnotetext{
${ }^{29}$ Cf. Huntington, Samuel; El conflicto entre civilizaciones, próximo campo de batalla, Valencia: Pretexto, 1986. Ciertamente, su perspectiva respecto de las condiciones de las nuevas relaciones globales son sesgadas y no reflejan la complejidad de los encuentros culturales y sociales en el mundo contemporáneo, como la cooperación, la asistencia, la interculturalidad, la migración, el sistema internacional de derechos humanos y el conjunto de garantías que son también apoyados por miembros de muchas de las civilizaciones que hoy en día supuestamente estarían en pie de lucha.
} 
de correr hasta que el amor no ilumine los espíritus y tenga la última palabra. Cualquiera que interprete la palabra de Dios, puede equivocarse y cometer errores, y con ello nuestro primer deber sería el de la tolerancia recíproca. Si todas las cuestiones fueran tan claras $y$ evidentes como que sólo hay un Dios, todos los cristianos podrían tener fácilmente una misma opinión sobre todas esas cuestiones,....pero como todo está oscuro y confuso, los cristianos no deben juzgarse los unos a los otros. Y si somos más sabios que los paganos, seamos también mejores y más compasivos que ellos. ${ }^{30}$

Puesto que la Verdad doctrinaria última es confusa y nadie puede estar seguro de tener la interpretación correcta, sólo queda la veracidad práctica que consiste en reconocer que no se tiene el dominio sobre la Verdad y tratar al otro compasivamente. Castellio lo subraya adecuadamente: si acaso somos mejores que los que no creen, ello no sería por que tenemos la doctrina correcta, o la única interpretación válida de las verdades de fe, sino en que somos compasivos, es decir, caritativos. Nuestra superioridad no sería teórica, sino práctica. Con ello se asienta el principio de la tolerancia desde Castellio hasta nuestros días. Y no se trata sólo de la tolerancia con los supuestos herejes que no creen de la manera en que nosotros creemos -, sino también con los supuestos impíos - quienes no creen en aquello que nosotros creemos.

Esto tiene consecuencias directas tanto para las relaciones entre los fieles en las comunidades religiosas (es decir, las relaciones al interior de las comunidades de creyentes) como para el diálogo ecuménico y el diálogo interreligioso (las relaciones y el diálogo entre las religiones). Al interior de las comunidades de fe la tolerancia basada en la caridad supone el respeto de los diferentes modos de creer en las verdades de fe. En lo referente al diálogo ecuménico e interreligioso, el soporte del mismo no puede ser una verdad doctrinal, en el sentido de una 'doctrina verdadera' que el otro tendría que asumir necesariamente como la única correcta para iniciar realmente el encuentro. No es posible iniciar el diálogo a partir de esa exigencia, ya que el otro podría condicionar a su vez el diálogo a que asumamos su doctrina, y no la nuestra, como la verdadera. En vez de ello, el diálogo ha de cimentarse en la veracidad, es decir, en la disposición moral a ser honesto con el otro, y el deseo profundo de ser compasivo con nuestros interlocutores. Ello supone reemplazar las doctrinas por la práctica de la caridad como fundamento del diálogo, además de que en el encuentro entre versiones del cristianismo y entre religiones nos acercamos con la disposición moral que nos haga desear construir un mundo en el que se permita a cada cual creer en libertad.

La disposición moral hacia la veracidad y la pretensión de tener la verdad última como actitudes para insertarnos en el diálogo sobre nuestras creencias religiosas y los diversos modos

${ }^{30}$ Citado en Zweig, Stefan; Castellio contra Calvino. Conciencia contra violencia. Barcelona: Acantilado, 2001,pp. 170-71. 
de asumirlas traen consecuencias radicalmente opuestas. Ser veraz significa ofrecer una actitud sincera al otro. La persona veraz no tiene como objetivo acceder a y mantener una verdad de principio a fin en el diálogo. La veracidad no se opone al error (como sí sucede con la verdad), sino con la mentira. Si las cosas de Dios son misteriosas para todos, si la verdad última respecto a lo religioso nos es oculta, entonces aquél que afirme tener la Verdad que debe condicionar el encuentro estaría mintiendo. Su mentira consiste en afirmar tener certeza respecto de algo que es para todo humano incierto. Ello no es una falta epistémica sino moral, pues lo que se muestra con ello es intransparencia. La veracidad es la apertura al otro de modo que manifestamos abiertamente los límites de nuestras certezas para poder abrir espacio a las dudas.
Esta disposición moral no es algo ajeno a las aspiraciones de las grandes religiones, como el cristianismo, el Islam, el judaísmo y el budismo, entre otras. La primacía de la compasión y la caridad se encuentran en el corazón de estas confesiones y todos los creyentes razonables de estas religiones entienden que éste es el foco de acuerdo sobre el que se construye el diálogo interreligioso. $\mathrm{Si}$ bien la presencia del terrorismo internacional de rostro islámico ha generado la imagen en el mundo contemporáneo que los musulmanes son violentos, irracionales y fanáticos, ello no refleja el corazón del Islam expresado tanto en el Corán como en la tradición islámica, en el que se enfatizan los mensajes de paz y tolerancia. El terrorismo islámico es tan representativo del Islam como lo son la Inquisición y Hitler del cristianismo. 


\section{Referencias}

- Arens, Eduardo. (2004). La Biblia sin mitos. Una introducción crítica, Lima: CEP.

- Berstein, Richard. (2006). El abuso del mal. La corrupción de la política y la religión desde el 11/9. Buenos Aires: Katz.

- Huntington, S.(1986). El conflicto entre civilizaciones, próximo campo de batalla. Valencia: Pretexto.
- Maalouf, Amin. (2002). Identidades asesinas. Madrid: Alianza Editorial.

- Sen, Amartya. (2007). Identidad y violencia. La ilusión del destino, Buenos Aires: Katz.

- Stuart Mil, John. (1979). Sobre la libertad, Madrid: Alianza Editorial.

- Zweig, Stefan. (2001). Castellio contra Calvino. Conciencia contra violencia. Barcelona: Acantilado. 